\title{
APPLICATION OF ANALOGUE DERIVATORS FOR OBTAINING DIRECT NON-MEASURABLE COMPONENTS OF THE STATE VECTOR IN CRANE CONTROL
}

\author{
GROSINGER Patrik ${ }^{1}$, ŠOLEK Peter $^{1}$ \\ ${ }^{1}$ Slovak University of Technology in Bratislava, Faculty of Mechanical Engineering, Institute of Applied \\ Mechanics and Mechatronics, Nám. Slobody 17,812 31 Bratislava, Slovakia \\ e -mail: patrik.grosinger@stuba.sk
}

\begin{abstract}
This paper presents a simple-to-use system for estimating non-measurable components of crane state vector considering parameter changes. To obtain them, it is possible to use a numerical derivative, where the measurement noise causes great inaccuracies, or the Luenberger observer and Kalman filter, which require knowledge of the dynamics of the controlled system, which is constantly changing with the crane.
\end{abstract}

KEYWORDS: crane control, analog state vector estimation, analog derivator

\section{Introduction}

Crane is in practice a very often used equipment. Its operation is not easy and brings many risks. Improper handling may result in the vibration load and consequently in a crash.

Almost of controllers of the gantry and overhead crane are designed based on the linearized model. The reason for the suitability of the linearized model is given, for example in [1]. With use an intelligent crane control techniques is possible a simplified a nonlinear crane dynamic model to linear system with varying parameters, like a rope length and payload mass, which can be used as key variables useful in anti-sway system designing. Planar models are used most frequently. They are used also in articles [2-12]. They are relatively simple and provide usable results.

One of the problems encountered in crane control is the measurement the swaying angle of load. Approaches to measuring the angle of vibration are generally discussed in [1]. Specific solutions for the laboratory crane are described in [2, 3, 5] and [8]. An innovative approach to estimate the vibration angle of load without measurement is given in [5]. For its computational demands in real time application requires crane modeling with PC. For the overhead crane or gantry crane, it is quite easy to measure the vibration angle because the length of the rope is relatively short. With a relatively small length displacement of the load, the vibration angle is significant. Articles $[2,3,5]$ take the angle measurement for a short rope. In this article, the vibration angle is measured. It is therefore a well-known component of the state vector

The main problem with crane control is the state vector estimate. Most modern control methods require its knowledge. The non-differentiate components of the state vector are the trolley displacement and the swaying angle of the load, in $[8,9,12]$ and the length of the rope. Derivation of state variables are directly unmeasurable.

This article discusses the hybrid estimation of individual derivations by means of operational amplifiers in the circuit as analog derivatives. These derivatives work in conjunction with a digital microcomputer, resulting in hybrid control. The advantage of this 
solution is that knowledge of system dynamics is not required to estimate the derivation of the individual variables. Also, the derivation is performed analogously in real time without the need for numerical calculation. Therefore, numerical filters of measured quantities or state estimators are not used. The resulting state vector control then does not need a powerful microcomputer. Analog values are converted to digital using AD converter. Calculation of the action variable using vector of controller parameters or control gain matrix, as in articles [3, 4, 18], then the calculation is very simple. The control of light damped systems, in this case beams, is also discussed in the publication [21]. Noise filtering issues are also discussed in [21]. The article [22] discusses the optimal control of a similar problem.

\section{Use of operating amplifiers when detecting derivatives of coordinates}

First, you need to analyze the planar dynamic crane model. From this model is further developed to define the state description and control proposal. The subject of the article is not to investigate the robustness of the proposed control, but to design a state vector estimation that is independent of the knowledge of the system parameters. Therefore, in crane model experiments, when changing parameters, the manual gain coefficients of the controller were changed, but the analog circuit settings used to estimate the state vector did not change.

\subsection{Planar crane model and its control using Pole Placement Method}

In articles $[2,5,6,7,10,11]$, the constant length of the rope is considered during the regulatory process. Thus, the length of the rope does not occur as a variable of the state vector. This exactly corresponds to the overhead crane, where the load is moved only on one of the axes. In other movements than lifting, the length of the rope does not change.

The planar model is in Fig.1. The resistance to trolley motion is introduced as viscous due to the linear state description. This simplification is used in $[6,7,11]$ and $[9,10,12]$, any effect of resistance to movement of the trolley is neglected. In the real overhead crane, of course, motion resistance is composed of the rolling friction between the trolley`s wheels and the viscous damping in the gearbox. In this model, the viscous damping of the pendulum (load) is also considered, although it is not mentioned elsewhere. It is for the sake of discovering transient and impulsive responses that vibration does not go on indefinitely.

The only way the crane can control is to act on the trolley by force. The effect of the disturbance on the system is possible by force acting on the load, as shown in Fig. In Fig.1. the individual markings are: $m_{1}$ is the weight of the trolley, $m_{2}$ is the weight of the load, 1 is the length of the rope, $b_{r}$ is the coefficient of the viscous damping during swaying, $b_{t}$ is the coefficient of viscous damping in the trolley's translational movement, $x$ is the trolley's coordinates, another $g$ is a gravitational acceleration. Position of load is defined in (1):

$$
x_{0}=x+l \sin \varphi \cong x+l \varphi
$$

The following deduction of equations in the state description is similar to $[6,7,10,11]$. To obtain the equations of motion using the Lagrange equations of the second order, it is necessary to describe it according to Fig.1, the kinetic energy $E_{K}$, the potential energy $E_{p}$, the dissipation energy $E_{D}$ of dynamic model of the crane (2). 


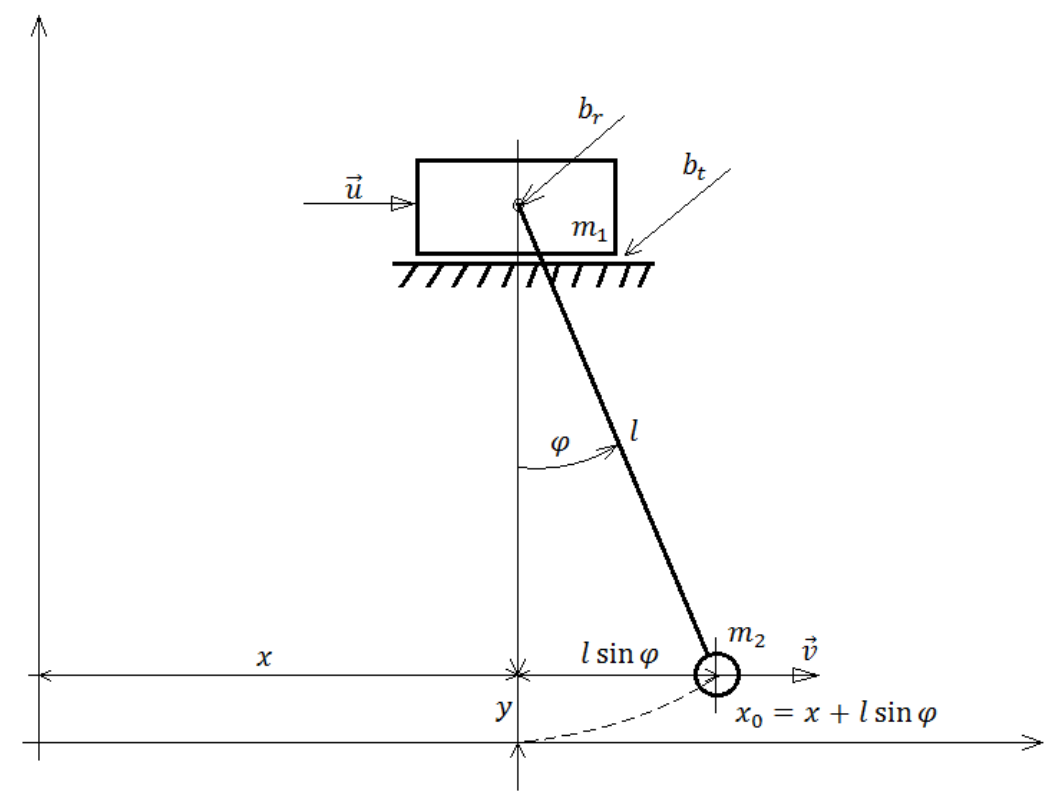

Fig. 1 Planar dynamic crane model

$$
\begin{gathered}
E_{K}=\frac{1}{2}\left(m_{1}+m_{2}\right) \dot{x}^{2}+m_{2} l \dot{x} \dot{\varphi} \cos \varphi+\frac{1}{2} m_{2} l^{2} \dot{\varphi}^{2} \\
E_{P}=m_{2} g l(1-\cos \varphi) \\
E_{D}=\frac{1}{2} b_{t} \dot{x}^{2}+\frac{1}{2} b_{r} \dot{\varphi}^{2}
\end{gathered}
$$

Lagrange`s equations of motion are described in (3):

$$
\frac{d}{d t}\left(\frac{\partial E_{K}}{\partial \dot{q}_{i}}\right)-\frac{\partial E_{K}}{\partial q_{i}}+\frac{\partial E_{P}}{\partial q_{i}}+\frac{\partial E_{D}}{\partial \dot{q}_{i}}=Q_{i}
$$

In equation (3) $q_{i}$ is the generalized coordinate taking $x, \varphi$ and $Q_{i}$ is the generalized force. Using the linearization assumptions for a small vibration angle, $\sin \varphi \cong \varphi, \cos \varphi \cong 1$ and using Lagrange equations, the linearized motion equations of the system are (4):

$$
\begin{gathered}
{\left[\begin{array}{cc}
m_{1}+m_{2} & m_{2} l \\
m_{2} l & m_{2} l^{2}
\end{array}\right]\left[\begin{array}{c}
\ddot{x}(t) \\
\ddot{\varphi}(t)
\end{array}\right]+\left[\begin{array}{cc}
b_{t} & 0 \\
0 & b_{r}
\end{array}\right]\left[\begin{array}{c}
\dot{x}(t) \\
\dot{\varphi}(t)
\end{array}\right]+\left[\begin{array}{cc}
0 & 0 \\
0 & m_{2} g l
\end{array}\right]\left[\begin{array}{c}
x(t) \\
\varphi(t)
\end{array}\right]} \\
=\left[\begin{array}{ll}
1 & 1 \\
0 & l
\end{array}\right]\left[\begin{array}{l}
u(t) \\
v(t)
\end{array}\right]
\end{gathered}
$$

In equation (4), $u(t)$ is control force and $v(t)$ is failure force. The control force acts on the trolley and the failure force acts on the load. To write equations of motions in the form of a state description, it is appropriate to mark the individual components in (4) in the form (5), where $\boldsymbol{M}$ is the mass matrix, $\boldsymbol{B}_{f}$ is the damping and $\boldsymbol{K}$ is the stiffness matrix

$$
\boldsymbol{M} \ddot{\boldsymbol{q}}(t)+\boldsymbol{B}_{f} \dot{\boldsymbol{q}}(t)+\boldsymbol{K} \boldsymbol{q}(t)=\boldsymbol{B}_{i} \boldsymbol{u}(t)
$$

Equation (6) is then overwritten following the adjustment to the state description:

$$
\begin{gathered}
\dot{\boldsymbol{x}}(t)=\boldsymbol{A} \boldsymbol{x}(t)+\boldsymbol{B u}(t) \\
{\left[\begin{array}{l}
\dot{\boldsymbol{q}}(t) \\
\ddot{\boldsymbol{q}}(t)
\end{array}\right]=\left[\begin{array}{cc}
\mathbf{0} & \mathbf{1} \\
-\boldsymbol{M}^{-1} \boldsymbol{K} & -\boldsymbol{M}^{-1} \boldsymbol{B}_{f}
\end{array}\right]\left[\begin{array}{l}
\boldsymbol{q}(t) \\
\dot{\boldsymbol{q}}(t)
\end{array}\right]+\left[\begin{array}{c}
\mathbf{0} \\
\boldsymbol{M}^{-1} \boldsymbol{B}_{i}
\end{array}\right] \boldsymbol{u}(t)}
\end{gathered}
$$


As will be described below, the directly measured components of the state vector are $x(t)$ and $\varphi(t)$ therefore the output equation of the state description in the form (7):

$$
\boldsymbol{y}(t)=\boldsymbol{C} \boldsymbol{x}(t)=\left[\begin{array}{llll}
1 & 0 & 0 & 0 \\
0 & 1 & 0 & 0
\end{array}\right]\left[\begin{array}{llll}
x(t) & \varphi(t) & \dot{x}(t) & \dot{\varphi}(t)
\end{array}\right]^{T}
$$

The system described by equations (6) and (7) is controllable and observable for all practical parameters. Controllability and observability are described in [14, 15, 18].

The Pole Placement Method, which is described in [18], was chosen for the system design proposal. This method is used as the basis for adaptive control of the TSK (Takagi Sugeno Kang) $[2,4,10]$. In all these articles, the action variable is proportional to the difference between the desired and the current state vector. According to [18], the action variable is defined in the form (8):

$$
u(t)=\boldsymbol{K}\left(\boldsymbol{x}_{\boldsymbol{d}}(t)-\boldsymbol{x}(t)\right)=\boldsymbol{K}\left(\left[x_{d}, 0,0,0\right]-[x, \varphi, \dot{x}, \dot{\varphi}]\right)^{T}
$$

Where $\boldsymbol{x}_{\boldsymbol{d}}(t)$ is the desired state vector and $\boldsymbol{K}=\left[k_{1}, k_{2}, k_{3}, k_{4}\right]$ controller gain matrix. To calculate the controller gain matrix, for control transmission, on the basis of stability, it is appropriate to specify $\boldsymbol{x}_{\boldsymbol{d}}=\mathbf{0}$ and also not to consider the effect of the disturbance force: $v=$ 0 . Under these conditions, after fitting (8) to (6), a set of equations (9) is obtained:

$$
\dot{\boldsymbol{x}}(t)=(\boldsymbol{A}-\boldsymbol{B} \boldsymbol{K}) \boldsymbol{x}(t)
$$

From the stability conditions of equations (9) a controller gain matrix $\boldsymbol{K}$ can be designed. This matrix can be calculated using Ackermann equations using MATLAB environment or derived exact relations [20]. The matrix of amplification of the controller $\boldsymbol{K}$ is different for each length of the rope and the weight of the load. The evolutionary optimization of the TSK of an adaptive controller that switches the individual controllers set for the boundary parameters is given in [2, 4]. It is no longer the subject of optimal control, therefore the experimentally selected poles in the stable region and the calculated gain matrix of the controller $\boldsymbol{K}$. The selected poles are in (10)

$$
p_{1}=-5.2 ; p_{2}=-6.2 ; p_{3}=-7,2 ; p_{4}=-8.2
$$

\subsection{Experimental device}

This device is a direct implementation of a planar dynamic model. Thus, it is not possible to move the trolley after two axes, but only one Fig.2. The model used in this article was inspired by the planar laboratory scaled model used in Article [8].

Trolley movement is provided by a DC motor controlled by pulse-width modulation via the H-bridge. The engine acts on the trolley through the rope. The trolley moves on two steel smooth rods. The length of the path the trolley can move is $0.26 \mathrm{~m}$. No rope is used to hang the load. But the rod. This is a limited vibration of load in the direction perpendicular to the trolley direction. The weighting container can be moved freely on the rod and contains a weight up to $0.7 \mathrm{~kg}$. The length after which the container can be moved over the bar is from $0.1 \mathrm{~m}$ to $0.45 \mathrm{~m}$ at a distance from the axis of rotation. In Tab. 1 we present the physical parameters of the model shown in Fig.2, which corresponds to the dynamic model in Fig.1.

The distance $x(t)$ from the starting position is determined using a specially designed potentiometer. The signal then enters the filtering and amplifying circuit, which provides an electrical voltage proportional to the position of the trolley in the range 0 to $5 \mathrm{~V}$.

The pendulum swaying angle $\varphi(t)$ is measured by the low cost rotary encoder CALT P3022. The shaft of this sensor is mounted on rolling bearings with very low friction resistance. The pendulum is mounted directly on this sensor. This way, the swaying of the 
load on the rope is properly imitated. At an initial displacement of $10^{\circ}$, a visible vibration takes about 5 minutes. The use of such a sensor to measure the angle of vibration was based on the articles $[3,5,7]$. In [3,5], however, the author uses a relatively large crane model with a load of $150 \mathrm{~kg}$ where the load is suspended on the rope and the rope rotates the sensor with a special lever with a cut. The sensor CALT P3022 has a voltage analogue output that is implemented with a 12-bit DA converter. The output voltage is in the range $0 \div 5 \mathrm{~V}$. The maximum voltage corresponds to the $360^{\circ}$ rotation.

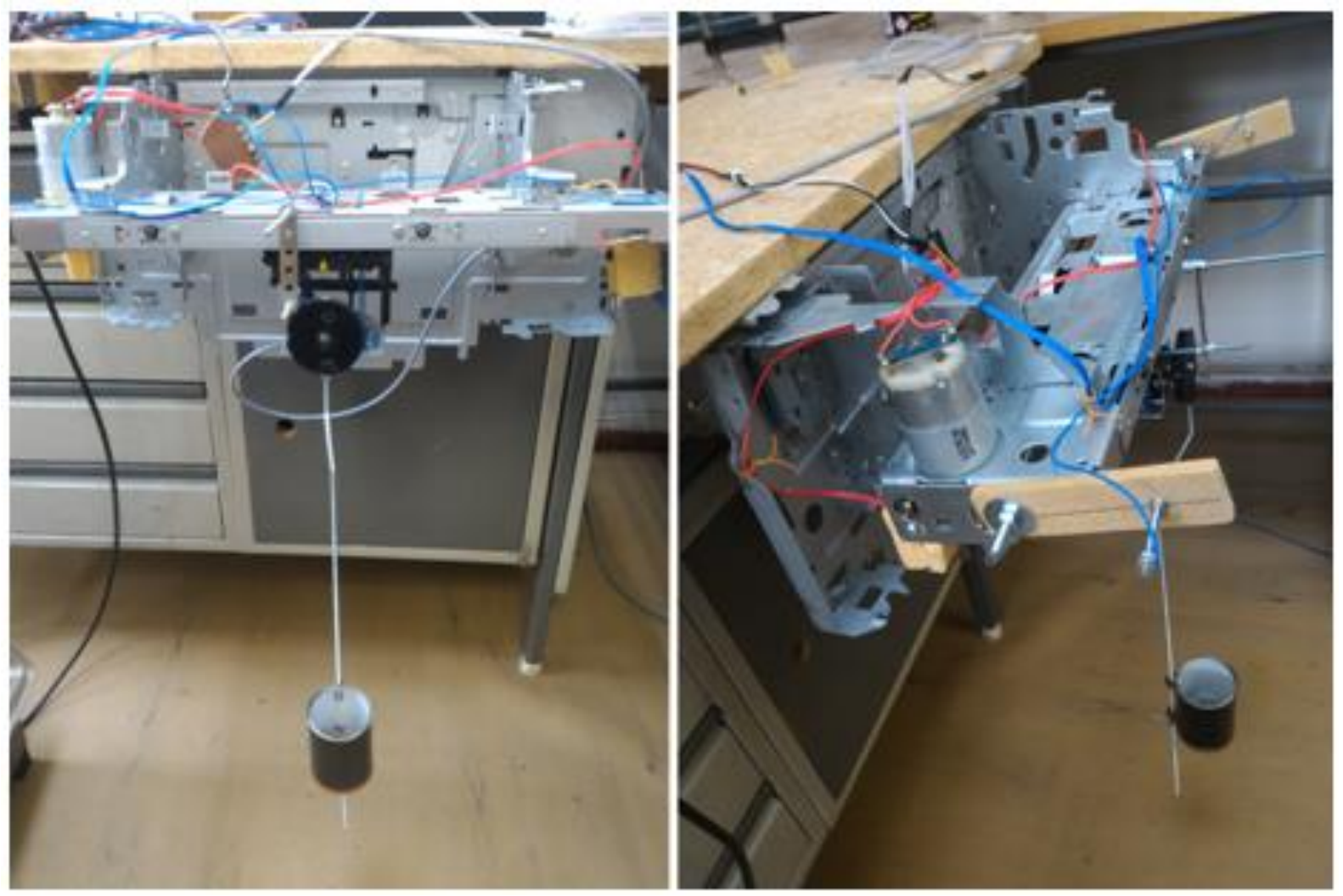

Fig. 2 Experimental crane model

Table 1. Values of physical parameters of laboratory scaled model by experiment

\begin{tabular}{|c|c|}
\hline Part of model & Value \\
\hline$m_{1}$ & $0.205 \mathrm{~kg}$ \\
\hline$m_{2}$ & $0.250 \mathrm{~kg}$ \\
\hline$l$ & $0.350 \mathrm{~m}$ \\
\hline$b_{t}$ approximately & $0.1 \mathrm{Nsm}^{-1}$ \\
\hline$b_{r}$ approxiamtely & $0.001 \mathrm{Nsm} \mathrm{rad}^{-1}$ \\
\hline
\end{tabular}

\subsection{Analog estimation of trolley distance and swaying angle derivations}

First, motivation to solve the problem in an analogous way is required. The numerical microcomputer is selected for calculating the action value through (8). Standard low cost 8-bit microcomputers are usually equipped with a 10-bit $\mathrm{AD}$ converter. This also produces a noise in the range of \pm 1 output value of the $\mathrm{AD}$ converter, even with a stable analogue input signal. This is only about $0.1 \%$ of the total range in the $2^{10}$ possible states the transducer takes. This deviation does not interfere with proportional operations or numerical integration. The problem occurs with a numerical derivation. The simplest is the numerical derivative $x(k T)$ expressed in (11), where $x(k T)$ is the deduced value from the AD converter at timet $=k T, T$ is the sampling period. 


$$
\dot{x}(k T) \cong \frac{1}{T}(x(k T)-x((k-1) T))
$$

If the sampling period of the mechanical process is equal to $0.01 \mathrm{~s}$, as is also the case in [12], in the case of a transducer error \pm 1 of the whole range, the derivation estimate is \pm 100 . Thus, if the analog input signal is in the range of $0 \div 5 \mathrm{~V}$, then after the AD converter an estimate is obtained with an accuracy of $\pm 0.005 \mathrm{~V}$. But in numerical derivation according to (11), the deviation from the real value is up to $0.5 \mathrm{~V}$, which is $10 \%$ of the measured signal range. Thus, it is not possible to estimate the course of the function derivation. It is possible to filter it with digital filters, but it provides a large phase delay for such noise.

Another option to find derivatives is to use estimators. The derivation of these algorithms which detect unknown components of the state vector are e.g. in [14, 15]. Luenberger observer is defined in the form (12) where $\boldsymbol{x}_{\boldsymbol{e s t}}$ is an estimated state vector, $\boldsymbol{L}$ is the observer gain matrix.

$$
\begin{gathered}
\boldsymbol{y}_{\text {est }}=\boldsymbol{C} \boldsymbol{x}_{\text {est }}, \\
\dot{\boldsymbol{x}}_{\text {est }}=\boldsymbol{A} \boldsymbol{x}_{e s t}+\boldsymbol{B u}+\boldsymbol{L}\left(\boldsymbol{y}-\boldsymbol{y}_{\text {est }}\right) .
\end{gathered}
$$

The disadvantage is that, on the design of the estimator in the form (12), it is necessary to know all the parameters of the system and, unlike the Kalman Filter, it does not consider uncertainties. When changing the parameters that are still in use while the crane is running, such an estimator provides incorrect outputs. Therefore, it is necessary to re-calculate the matrix $\boldsymbol{L}$ with each parameter change and this is disadvantageous for real-time applications.

Another frequently used option is the Kalman Filter and its modifications as the Extended Kalman Filter [13] and the Unscented Kalman Filter [8]. As this article deals with the use of a simple approach providing reasonable results.

For these reasons, this work proposes an analog approach to estimating unknown derivations. An analog derivative in the simplest connection can not be used because it also derives signal source noise. For filtration, [16] there is a modified derivative connection that filters unwanted noise and only derives the carrier signal component. The connection is on Fig.3.

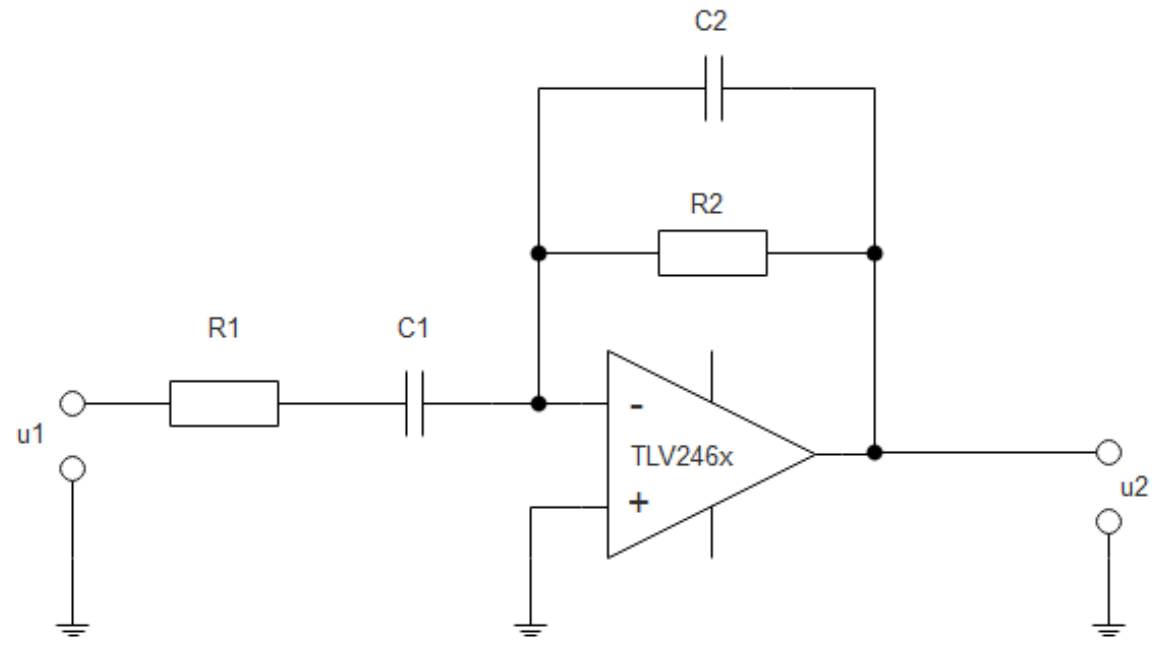

Fig. 3 Analog differentiator with noise filtering

In simple terms, the capacitor $C_{1}$ and the resistor $R_{2}$ provide the input signal derivation and the capacitor $C_{2}$ with the resistor $R_{1}$ to provide filtration of noise. For the direct and reverse connection branch on Fig.3. the individual impedances are (13): 


$$
Z_{1}(j \omega)=\frac{R_{1} C_{1} j \omega+1}{C_{1} j \omega} ; Z_{2}(j \omega)=\frac{R_{2}}{R_{2} C_{2} j \omega+1}
$$

Using the rules generally applicable to operational amplifiers and using the relationship $s=j \omega$ the resulting transfer of the derivative (14) is obtained.

$$
A(s)=\frac{u_{2}(s)}{u_{1}(s)}=-\frac{R_{2} C_{1} s}{\left(R_{1} C_{1} s+1\right)\left(R_{2} C_{2} s+1\right)}
$$

The values of passive components calculated according to (14) used for the constructor of the differentiator in Fig.3. are in Table 2.

Table 2. Values of used parts

\begin{tabular}{|c|c|}
\hline Parts & Values \\
\hline$R_{1}$ & $1.2 \mathrm{k} \Omega$ \\
\hline$R_{2}$ & $33 \mathrm{k} \Omega$ \\
\hline$C_{1}$ & $1 \mu \mathrm{F}$ \\
\hline$C_{2}$ & $10 \mathrm{nF}$ \\
\hline
\end{tabular}

In relation (14) of the product $R_{2}$ and $C_{1}$, it expresses the amplification of the differentiator. This was experimentally determined at 0.33 . The denominator of the expression (14) indicates that the resulting join is an ideal differentiator with added second order inertia. On Fig.4. is the Bode diagram of the described differentiator obtained using the MATLAB environment toolbox.

Logarithm of the expression (14), followed by substituting asymptotic sub-transmission, and the summing can be approximately expressed extreme amplitude-frequency response of the equation (15). The chosen extreme amplitude-frequency characteristic is at $450 \mathrm{~Hz}$. At this frequency, all of your own circuit noise is safely filtered out.

$$
\frac{1}{2 \pi R_{1} C_{1}} \cong \frac{1}{2 \pi R_{2} C_{2}} \cong 450 \mathrm{~Hz}
$$

Values $R_{1}$ and $C_{2}$ in Table 2 are closest available to those calculated by (15). The proposed differentiator is implemented in the general inverting circuit of the operational amplifier. For this reason, the phase shift of the derivative is in the range of approximately $270^{\circ}$ to $90^{\circ}$. After multiplying in a microcomputer with a value of -0.33 , the estimate of the differentiator will be approximately equal to the real coordinate derivation and phase shift in the $90^{\circ}$ to $-90^{\circ}$ range.

The analogue output from the CALT P3022 sensor is realized by a zero order shaper form circuit. This causes the output signal to consist of "stairs". These do not appear at the output of the differentiator when the differentiator is involved.

\subsection{Simulations and experimental results}

The block diagram of the controlled system is in Fig. 5. The real crane is replaced by the linear model (6) and (7), the transfer functions of the derivatives are (14).

Microcomputer on Fig. 5 serves to convert electrical voltages into states variables. They are multiplied by controller gain matrix $\boldsymbol{K}$. The sampling period is selected $\mathrm{T}=0.01 \mathrm{sec}$ as in [12]. Subsequently, the action variable is converted to the PWM signal.

The transport delay at the output of the microcomputer shows the delay caused by the zeroorder form factor and is according [18] big as $0.5 \mathrm{~T}=0.005 \mathrm{sec}$. In simulations and experiments, this transport delay has no impact. 


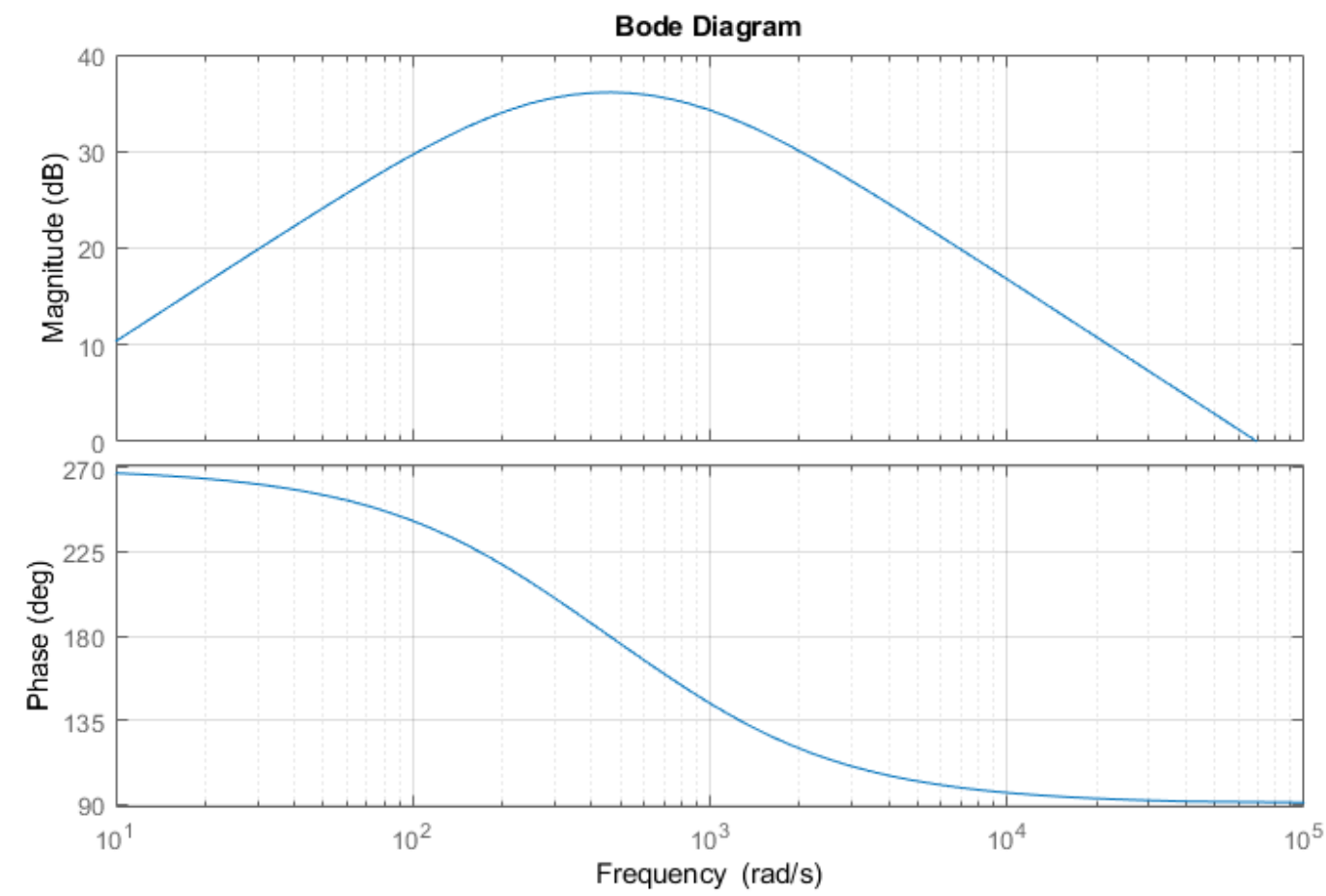

Fig. 4 Bode diagram of differentiator with filtering with concrete used parts

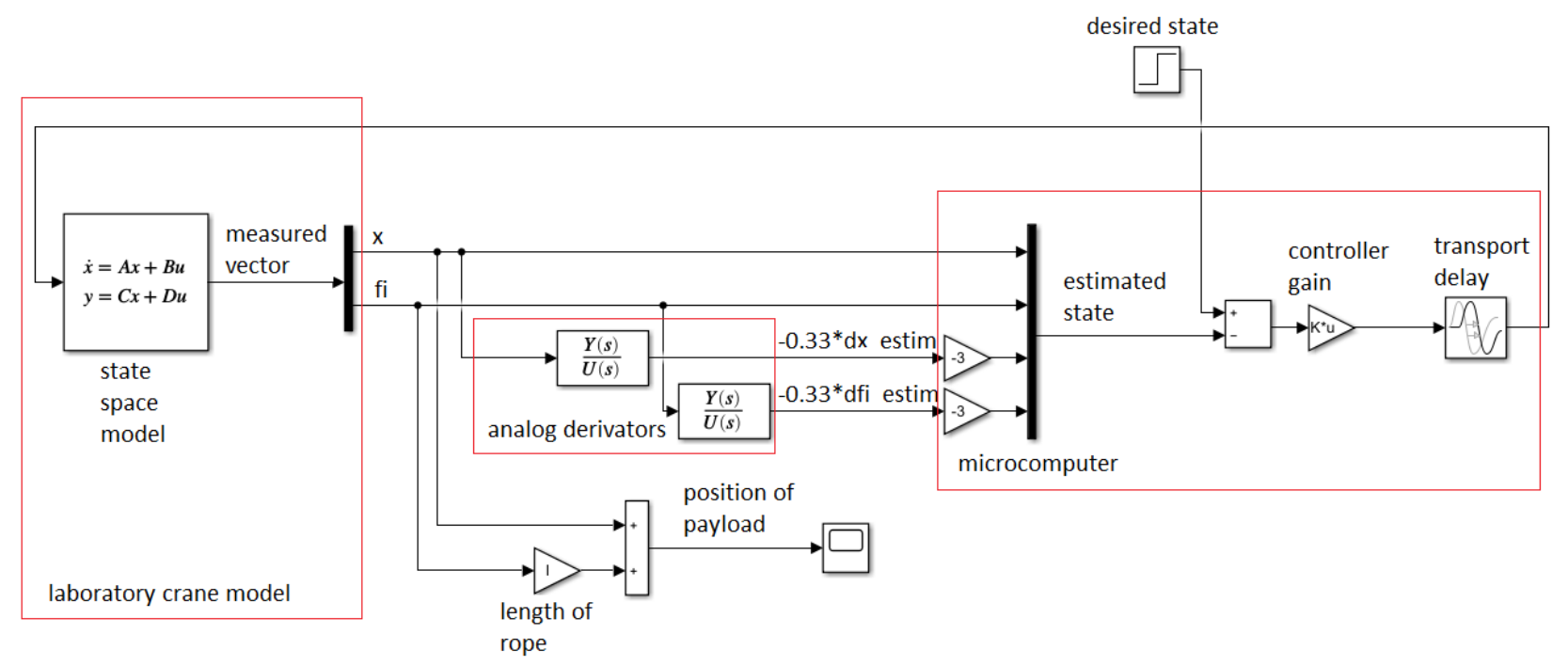

Fig. 5 Block diagram of controlled system in SIMULINK 


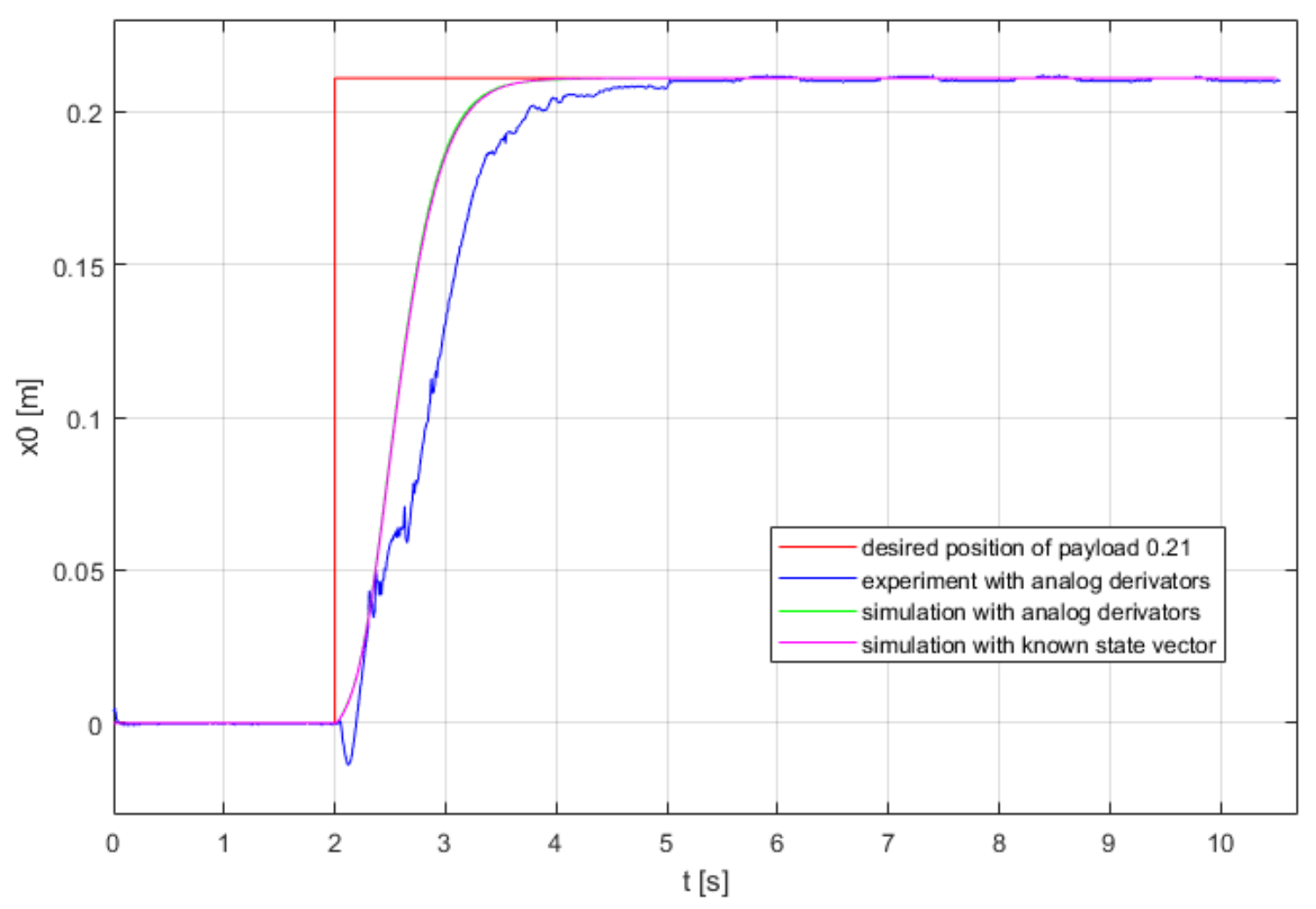

Fig.6. Comparison of experimental and simulation results

In Fig. 6 is a comparison of the simulation of controlling the ideal system with the known state vector (pink curve), controlling the ideal system with unknown derivatives estimated by the differentiators Fig. 5 (green curve), measured experiment data (blue curve).

When the values of the components of the analogue differentiator are used, the phase shift and the amplitude decay are not more pronounced. Fig. 7 is a comparison of the estimate of a trolley position derived by an analog differentiator with a known derivative from the state vector. It is evident that the deviation between the derivation estimate and the derivation obtained from the state vector is minimal. The described component of the state vector and its estimation by the derivative are obtained from the simulation shown in Fig. 5.

\subsection{Used operational amplifier and microcomputer}

The operating amplifier was chosen by the Texas Instruments TLV246x. The choice of suitable operational amplifiers for various applications is initially addressed in the publication [17]. TLV246x have an input differential amplifier realized from FET transistors, i.e. the input bias current is practically negligible. Therefore, there is no need for a compensating resistor in the non-inverting input, as shown in Fig. 3. These operational amplifiers belong to the Rail-to-Rail category. The maximum allowed supply voltage is $\pm 3 \mathrm{~V}$. For this reason, the operational amplifier can be directly connected to the microcontroller power supply. The disadvantage of TLV246x is too large a phase-frequency dependence. Capacitor $C_{1}$ is a high quality roll with polypropylene dielectric. An electrolytic capacitor [16, 17] can not be used.

In the experiment, the microcomputer used is Atmel AVR ATmega8 with a $16 \mathrm{MHz}$ clock rate. 


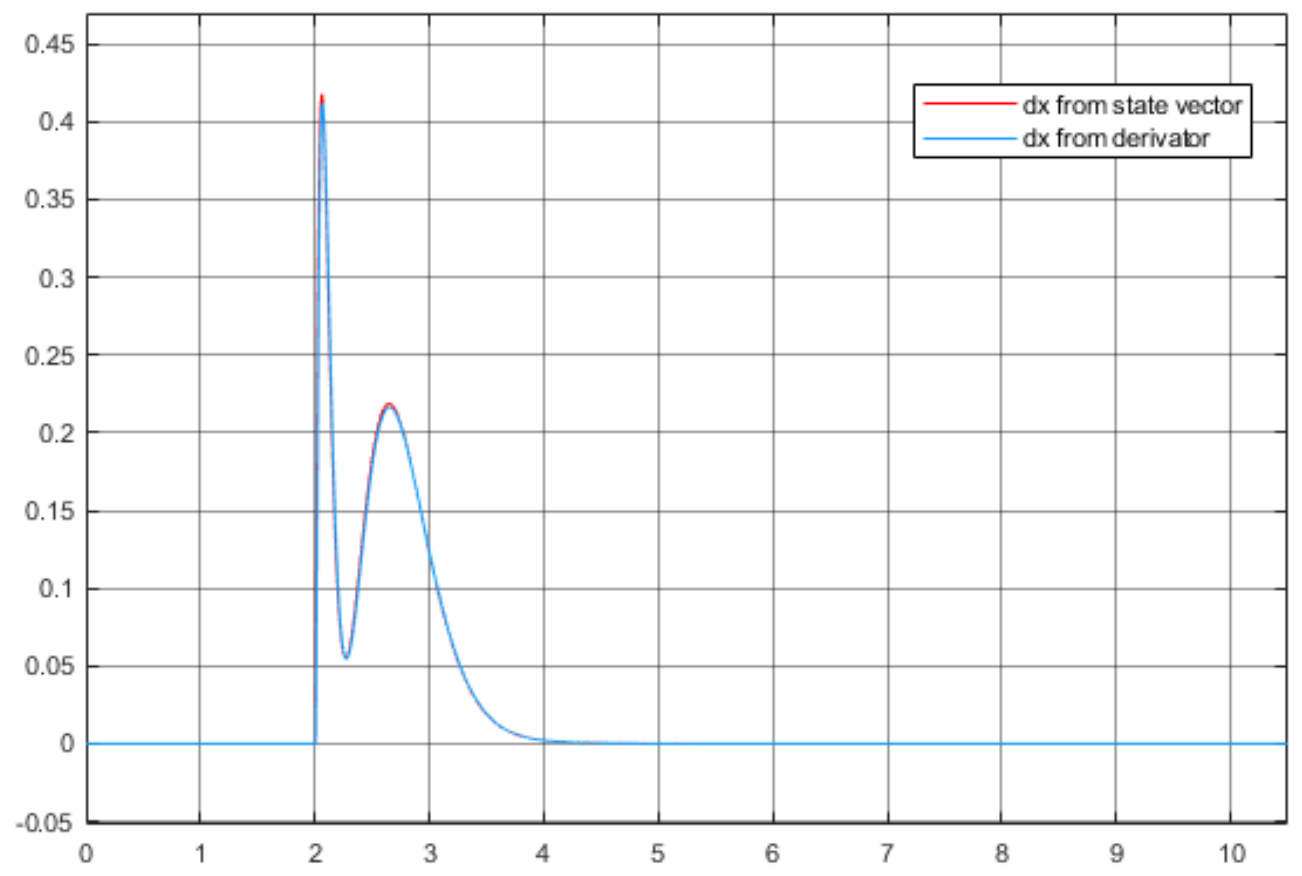

Fig.7. Comparison between analog estimated derivation of position of trolley and derivation from state vector

\section{CONCLUSION}

The article describes a non-standard and easy-to-use state vector estimate for crane control. This estimate, with respect to the simple realization, yields acceptable results as shown in Fig.7. The assumption is that the vibration angle and distance cats are measurable, which according to $[2,3,4,5,8]$ feasible. Unlike variations of Kalman filters, this approach does not account for the angle of the swaying and derivative components of the state vector, but the state estimate does not need to know the dynamics of the system. What is the benefit of using this estimate in conjunction with robust control.

The described derivation estimate is also applicable to other systems, such as cranes. This estimate can also be used in conjunction with digital output measuring devices but with an integrated controller with DA converter.

The implementation features used are low cost category and provide usable controllability of the laboratory scaled model of crane. What is the advantage of this solution compared to PLC systems.

\section{REFERENCES}

[1] Hyla, P. "The Crane Control Systems: A Survey", In: 17th International Conference on Methods and Models in Automation and Robotics, Miedzyzdroje, Poland, pp. 505 509, 2012.

[2] Smoczek, J., Szpytko, J. "Evolutionary algorithm-based design of a fuzzy TBF predictive model and TSK fuzzy anti-sway crane control system", Engineering Applications of Artificial Intelligence 28, pp. $190-200,2014$. DOI: 10.1016/j.engappai.2013.07.013

[3] Smoczek, J., Szpytko, J., "Fuzzy Logic-based Adaptive Control System Prototypying for Laboratory Scaled Overhead Crane", In: 2013 18th International Conference on 
Methods \& Models in Automation \& Robotics (MMAR), Miedzyzdroje, Poland, pp. 92 - 97, 2013. DOI: 10.1109/MMAR.2013.6669887

[4] Smoczek, J. "Evolutionary optimization of interval mathematics-based design of a TSK fuzzy controller for anti-cway crane control", International Journal of Applied Mathematics and Computer Science 23 (4), pp. 749 - 759, 2013. DOI: 10.2478/amcs2013-0056

[5] Smoczek, J. "Fuzzy crane control with sensorless payload deflection feedback for vibration reduction”, Mechanical Systems and Signal Processing 46 (1), pp. 70 - 81, 2014. DOI: 10.1016/j.ymssp.2013.12.012

[6] Ranjbari, L. "Designing precision fuzzy controller for load swing of an overhead crane", Neural Computing and Applications 26 (7), pp. 1555 - 1560, 2015. DOI: $10.1007 / \mathrm{s} 00521-015-1825-\mathrm{z}$

[7] Aschemann, H. "Disturbance estimation and compensation for trajectory control of an overhead crane", In: Proceedings of the 2000 American Control Conference, Chicago, Illinois, pp. 1027 - 1031, 2000.

[8] Patartics, B., Kiss, B. "Application of laser slot sensors for the state estimation of overhead cranes", Proceedings of the 2015 20th International Conference on Process Control, Strbske Pleso, Slovakia, pp. 387 - 392, 2015.

[9] Ngo, QH., Nguyen, NP., Nguyen, CN., Tran, TH., Hong, KS. "Fuzzy Sliding Mode Control of Container Cranes", International Journal of Control, Automation and Systems 13 (2), pp. 419 - 425, 2015. DOI: 10.1007/s12555-014-0150-0

[10] Wang, LF., Zhang, HB., Kong, Z. "Anti-swing Control of Overhead Crane Based on Double Fuzzy Controllers", In: 2015 27th Chinese Control and Decision Conference, Qingdao, Peoples R. China, pp. 981 - 986, 2015.

[11] Moradi, H., Vossoughi, G. "State estimation, positioning and anti-swing robust control of traveling crane-lifter system", Applied Mathematical Modelling 39 (22), pp. 6990 7007, 2015. DOI: 10.1016/j.apm.2015.02.039

[12] Frikha, S., Djemel, M., Derbel, N. "A New Adaptive Neuro-sliding Mode Control for Gantry Crane", International Journal of Control, Automation and Systems 16 (2), pp. 559 - 565, 2018. DOI: $10.1007 / \mathrm{s} 12555-017-0070-\mathrm{x}$

[13] Schaper, U., Sawodny, O., Zeitz, M., Schneider, K. "Load Position Estimation for Crane Anti-sway Control Systems", Journal of Dynamic Systems Measurement and Control, Volume 136 (3), 2014. DOI: 10.1115/1.4026134

[14] Inman, D. "Vibration with control", 1th ed., John Willey \& Sons, West Sussex, England, 2006. ISBN 0-470-01051-7

[15] Starek, L. "Kmitanie s riadením", 1th ed., Nakladatel'stvo STU, Bratislava, Slovakia, 2009. ISBN 978-80-227-3227-7

[16] Kabeš, K. “Operační zesilovače v automatizační technice”, 1th ed., Nakladatelsví technické literatury, Praha, Czechoslovakia, 1988.

[17] Dostál, J. "Operační zesilovače”, BEN - technicka literatura, Praha, Czech Republic, 2005. ISBN 80-7300-049-X

[18] Tewari, A. "Modern Control Design with Matlab and Simulink", John Willey \& Sons, West Sussex, England, 2002. ISBN 0-471-496790 
[19] Balátě, J. “Automatické řízení”, BEN - technická literatura, Praha, Czech Republic, 2003. ISBN 80-7300-0202

[20] Grosinger, P., Šolek, P. "Crane Control with Pole Placement Method and with PID Controller", presented at ERIN, Častá, Slovakia, May, 2018.

[21] Tůma, J., Šuránek, P., Žiaran, S. "All-Pass Filters in the Systems of Active Vibration Control of Weakly-Damped Systems", Strojnícky časopis - Journal of Mechanical Engineering 68 (4), pp. 65 - 74, 2018, DOI: 10.2478/scjme-2018-0048

[22] Likaj, R., Shala, A. "Optimisation and Control of Vehicle Suspension Using Linear Quadratic Gaussian Control”, Strojnícky časopis - Journal of Mechanical Engineering 68 (1), pp. 61 - 68, 2018. DOI: 10.2478/scjme-2018-0006 